Relations industrielles

Industrial Relations

\title{
Sécurité de la famille ouvrière
}

\section{Gérard Tremblay}

Volume 6, numéro 2, mars 1951

URI : https://id.erudit.org/iderudit/1023243ar

DOI : https://doi.org/10.7202/1023243ar

Aller au sommaire du numéro

Éditeur(s)

Département des relations industrielles de l'Université Laval

ISSN

0034-379X (imprimé)

1703-8138 (numérique)

Découvrir la revue

Citer cet article

Tremblay, G. (1951). Sécurité de la famille ouvrière. Relations industrielles /

Industrial Relations, 6(2), 34-34. https://doi.org/10.7202/1023243ar

Tous droits réservés @ C Département des relations industrielles de l’Université Laval, 1951
Ce document est protégé par la loi sur le droit d'auteur. L'utilisation des services d'Érudit (y compris la reproduction) est assujettie à sa politique d'utilisation que vous pouvez consulter en ligne.

https://apropos.erudit.org/fr/usagers/politique-dutilisation/ 


\section{Sécurilé de la famille ouvrière}

Notre sixième Congrès des relations industrielles aura lieu les 23 et 24 avril prochain. Comme d'habitude, ses séances se dérouleront dans la grande salle de spectacle du Château Frontenac, si accueillante et assez vaste pour accommoder une assistance de quatre à cinq cents personnes.

Le thème du Congrès, comme on le voit à l'en-tête de cette note, sera: * Sécurité de la famille ouvrière ».

Nous nous éloignons intentionnellement du champ immédiat des relations industrielles pour nous élever au plan supérieur de la sécurité de la famille ouvrière qui constitue l'aspect le plus important de la sécurité sociale.

Déjà, dans cing Congrès antérieurs, on se le rappelle, nous avions centré nos études et délibérations sur les thèmes suivants: Les relations industrielles dans le Québec, (1946); convention collective et sécurité syndicale, (1947); formes de collaboration patronale-ouvrière, (1948); techniques des relations de travail, (1949); structure des salaires, (1950).

Le Département des relations industrielles estime que, sans avoir épuisé tout le vaste sujet des relations patronales-ouvrières, il a du moins souligné l'importance de ses multiples aspects.

L'évolution sociale nous dirige maintenant vers d'autres études, d̀ caractère plus serein mais dont on ne saurait minimiser l'importance et l'actualité.

Est-ce à dire que la sécurité de la famille ouvrière est étrangère aux saines relations de travail? Que non; bien au contraire, elle les enveloppe, elle se constitue pour ainsi dire cause et effet de celles-ci.

Dans l'immédiat, de plus en plus nous notons que le champ des négociations collectives s'élargit pour s'étendre maintenant à la sécurité des travailleurs: emploi garanti, protection contre les risques maladie, invalidité, vieillesse, coopératives d'habitations, etc...

Nous donnons ci-après le sujet des conférences qui seront présentées; elles sont liéés les unes aux autres et se complètent en un faisceau puissant, magnifique, inspirateur, n'en doutons pas, d'initiatives heureuses pour le bien du peuple.

Associations ouvrières et patronales, comités paritaires, fonctionnaires, économistes et sociologues trouveront, dans ces assises, non seulement l'occasion de contacts sociaux renouvelés mais aussi une opportunité de s'instruire en écoutant de doctes conférences, d'exprimer leurs opinions dans les forums populaires et de collaborer aussi d̀ l'édification de la vraie cité démocratique et chrétienne.

\section{Le Directeur.}

Nous avons lassurance que la participation d ce sixième Congrès des relations industrielles sera aussi nombreuse et intéressée qu'd celui de lan dernier. On pourra lire en page 63 les informations relatives au Congres. 